\title{
UMA VISÃO DO TRATAMENTO MULTIDISCIPLINAR EM ALUNOS COM SÍNDROME DE DOWN NA APAE/ PASSO FUNDO: RELATO DE PROJETO DE EXTENSÃO
}

A vision of the multidisciplinary treatment in students with Down syndrome in APAE/ Passo Fundo: extension project's report

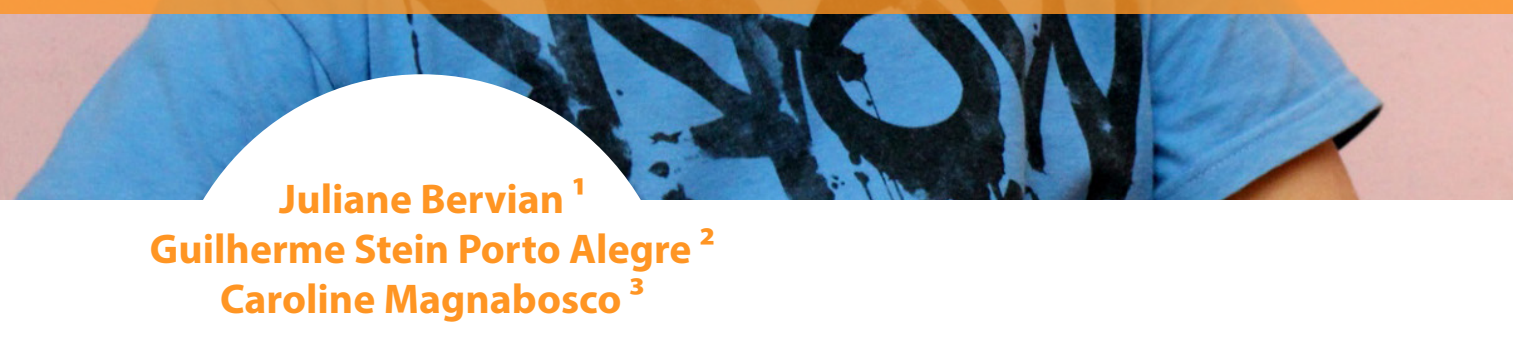

RESUMO

Síndrome de Down é um distúrbio genético caracterizado pela presença de um cromossomo 21 extra. A trissomia do 21 é a condição aneuplóide mais comum compatível com a sobrevida a termo. Esse estudo tem como objetivo relatar um projeto de extensão, com uma experiencia de integração da odontologia em outras áreas do conhecimento. Busca demonstrar a vivência dos alunos de odontologia da Universidade de Passo Fundo (UPF), dentro da APAE (Associação de Pais e Amigos dos Excepcionais), com uma proposta de descrever, de forma multidisciplinar, as várias terapias que norteiam um atendimento com pacientes que possuam Síndrome de Down. Além dos acadêmicos terem realizado o atendimento odontológico e verificado as características da síndrome na área específica da odontologia, também participaram das atividades em outras áreas. A conclusão deste estudo reforça a importância da multidisciplinariedade e da interdisciplinaridade, mas, tráz, também, a oportunidade da vivência do aluno de graduação no ambiente da escola. O momento ímpar de sair do território acadêmico e ter a liberdade de viver uma nova experiência.

Palavras chave: Síndrome de Down. Reabilitação.Criança.

\footnotetext{
1 Doutora em Odontopediatria e professora na Faculdade de Odontologia, na Universidade de Passo Fundo. E-mail: jbervian@upf.br

2 Cirurgião Dentista na Universidade de Passo Fundo. E-mail: guilherme.portoalegre@gmail.com

${ }^{3}$ Aluna de graduação na Faculdade de Odontologia, na Universidade de Passo Fundo.

E-mail: carolmagnabosco@msn.com
} 
Down syndrome is a genetic disorder characterized by the presence of an extra 21 chromosome. Trisomy 21 is the most common aneuploid condition compatible with full-term survival. This study aims to report an extension project, with an experience of integrating dentistry into other areas of knowledge. It seeks to demonstrate the experience of dentistry students at the University of Passo Fundo (UPF), within the APAE (Association of Parents and Friends of the Exceptional), with a proposal to describe, in a multidisciplinary way, the various therapies that guide the care to people with Down syndrome. Aside from performing the dental care and verifying the characteristics of the syndrome in the specific area of dentistry, the academics also participate in activities in other areas. The conclusion of this study reinforces the importance of multidisciplinarity and interdisciplinarity, it also offers an oportunity for the undergraduate student to have experiences in the academic environment. The single moment to leave the academic territory and have the freedom of living a new experience.

Keywords: Down syndrome. Rehabilitation. Child.

\section{INTRODUÇÃO}

A trissomia do $21(47, \mathrm{XY},+21$ ou $47, \mathrm{XX},+21)$ é a condição aneuplóide mais comum compatível com a sobrevida a termo. Essa trissomia produz a síndrome de Down, um fenótipo originalmente descrito por John Langdon Down, em 1866. Quase 100 anos se passaram entre a descrição de Down e a descoberta, em 1959, de que esse distúrbio é causado pela presença de um cromossomo 21 extra (HADDAD, 2007). Essa síndrome tem origem na fase de formação dos gametas ou logo após a fecundação, por separação inadequada dos cromossomos 21 , respectivamente na meiose ou na mitose (BERTHOLD et al., 2004).

Sua fisionomia é bastante característica observando ponte nasal baixa, fendas palpebrais elevadas, orelhas pequenas e dobradas, maxilar achatado (STRACHAN; READ, 2002). Pode ser notada durante a infância, alteração no pescoço, mãos e pés largos e curtos, com $50 \%$ apresentando uma dobra profunda em suas palmas (denominada linha simiesca). Vários problemas sistêmicos ocorrem com frequência entre os neonatos bem como nas crianças sindrômicas. Cerca de $40 \%$ dos pacientes apresentam cardiopatia congênita, em 3 a 7,5\% são observados defeitos no tubo digestivo, além de susceptibilidade aumentada às infecções do trato gastrointestinal, respiratórias e urinárias, devido à deficiência imune do sistema de linfócitos T. Há maior risco do desenvolvimento de leucemia ( 15 a 20 vezes mais, quando comparados com indivíduos normais e com hipotireoidismo (cerca de 8 vezes mais frequente) (HADDAD, 2007). 
O conhecimento da síndrome de Down é de grande interesse para o cirurgião-dentista, pois seus portadores apresentam uma série de alterações craniofaciais e dentárias. Estima-se que, no Brasil, apenas poucos dentistas sejam habilitados a atender a esse grupo de pacientes especiais, cujo tratamento se torna dificultado pelo pouco conhecimento acerca das suas principais características bucais (SANTAGELO et al., 2008).

A legislação brasileira através do Conselho Federal de Odontologia, por meio de sua resolução 22/2001, artigo 31, normatiza a odontologia para pacientes com necessidades especiais como a especialidade que tem por objetivo o diagnóstico, a prevenção, o tratamento e o controle dos problemas de saúde bucal dos pacientes que apresentam uma complexidade no seu sistema biológico e/ou psicológico e/ou social, bem como percepção e atuação dentro de uma estrutura transdisciplinar com outros profissionais de saúde (PERES et al., 2005).

$\mathrm{Na}$ Odontologia, características específicas são citadas para os pacientes com síndrome de Down. O paciente apresenta cavidade oral de tamanho reduzido, alterações nos órgãos que compõem o sistema estomatognático, ocasionando distúrbios fonoarticulatórios. A hipotonia muscular provoca um desequilíbrio de forças entre os músculos orais e faciais, alterando a arcada dentária, dando um aspecto de projeção mandibular e contribuindo para que a língua assuma uma posição inadequada. A respiração oral, além de deixar a criança mais suscetível a infecções respiratórias, altera seu palato e dificulta a articulação dos sons, sendo as alterações na fala um dos maiores problemas existentes nestes indivíduos (BARATA; BRANCO, 2010).

Segundo Santos e Morizon (1999), existe um consenso entre os especialistas que, o apoio clínico, educacional e social são essenciais para melhorar a qualidade de vida de crianças com Síndrome de Down, aumentando assim sua independência e inclusão social. A lei 4.024/61 artigo 88, assegura que a educação de pacientes especiais deve no que for possível, enquadrar-se no sistema geral de educação, a fim de integrá-los na comunidade (KASSAR; REBELO, 2011). O sistema de inclusão identifica os alunos com menor comprometimento intelectual e auxilia a introdução dos mesmos nas escolas da rede pública (SILVA; CRUZ, 2009). Aos outros, com maior comprometimento, as escolas do tipo APAE configuram uma alternativa, funcionando como escola inclusiva oferecendo ambientes favoráveis à concessão de oportunidades iguais e participação plena, seu sucesso exige esforço conjunto, não somente de professores e funcionários da escola como também de alunos, pais, familiares e voluntários (DURCE et al., 2006).

Neste ambiente são desenvolvidas terapias com o propósito de aumentar o rendimento intelectual, melhorar a aparência física e diminuir as infecções. E, além disso, o amor recebido pelas crianças e a aceitação familiar são considerados o melhor remédio para a melhora da qualidade de 
vida. Esse trabalho teve como objetivo, relatar o trabalho multidisciplinar em pacientes com Síndrome de Down realizados na escola, de forma a conhecer e descrever as principais alterações nas diferentes áreas de competência ofertadas pela escola.

METODOLOGIA

No ambiente da escola, desenvolve-se, desde 2013 até os dias atuais, um Projeto de Extensão denominado "Atenção Odontológica Integral e Interdisciplinar em Pacientes com Necessidade Especiais na APAE de Passo Fundo - RS". Neste projeto de extensão, os alunos do Curso de Odontologia da UPF realizam atendimento odontológico e também acompanham as outras atividades da APAE de forma integral.

Este relato, faz parte de uma experiencia realizada por um semestre apenas com alunos portadores de Síndrome de Down. Pode também ser chamado de sub projeto, uma vez que trabalhou apenas com uma parte da população da escola e apenas por um semestre.

Neste período, portanto, foram organizadas atividades semanais para os alunos e ocorreu a integração da odontologia nas atividades multidisciplinares. Ou seja, os alunos da odontologia não ficaram apenas no consultório odontológico da instituição.

Este estudo relata esta experiencia, de integração da odontologia em outras áreas do conhecimento. Busca demonstrar a vivencia dos alunos de odontologia dentro da APAE, com uma proposta de descrever, de forma multidisciplinar, as várias terapias que norteiam um atendimento com pacientes que possuam Síndrome de Down.

\section{Sujeitos}

Foram avaliados os pacientes com síndrome de Down frequentadores da instituição APAE no município de Passo Fundo - RS, durante o período de março a julho de 2015.

\section{Coleta de Dados}

Para a coleta de dados os acadêmicos de odontologia acompanhavam os atendimentos dos pacientes com síndrome de Down em outras áreas. Também foi proposto avaliação e atendimento odontológico, mas este não era o centro nem o único tratamento avaliado, e sim entender e conhecer as outras alterações que ocorrem com estes pacientes, bem como a forma como os outros profissionais trabalham e quando possível a troca de informações para a melhor conduta e qualidade do tratamento. 


\section{Na Odontologia}

\section{Exame clínico}

Os exames foram realizados utilizando espelho bucal plano, sonda periodontal. O local para realização dos exames foi o próprio consultório odontológico que existe instalado na APAE. A sequência de exames foi executada obedecendo à ordem da ficha clínica utilizada na escola: cárie dentária, oclusopatias, alterações odontogênicas, doença periodontal, bruxismo e alterações musculares.

\section{Teste salivar}

Investigou-se nos pacientes o $\mathrm{pH}$ bucal .Neste exame $1 \mathrm{~mL}$ de saliva foi coletada com uma seringa hipodérmica (Figura 1) e misturada com ácido, $3 \mathrm{~mL}$ de ácido clorídrico $0,005 \mathrm{~N}$ em tubos de ensaio estéreis com tampa (Figura 2).

Depois de realizada a mistura no tubo de ensaio, foi respeitado o tempo de dez minutos em descanso. Após este tempo, foi executado o teste com fitas de $\mathrm{pH}$ (Fusion/ Universal®). Nesse teste as fitas foram mergulhadas na saliva com ácido, interagindo por três segundos (Figura 3), em seguida efetivou-se a leitura da fita. A alteração de cor que ocorreu na fita foi comparada com a tabela cedida pelo fabricante. Por aproximação, a cor da fita e da tabela do fabricante eram confrontadas e obtinha-se o $\mathrm{pH}$ salivar do paciente.
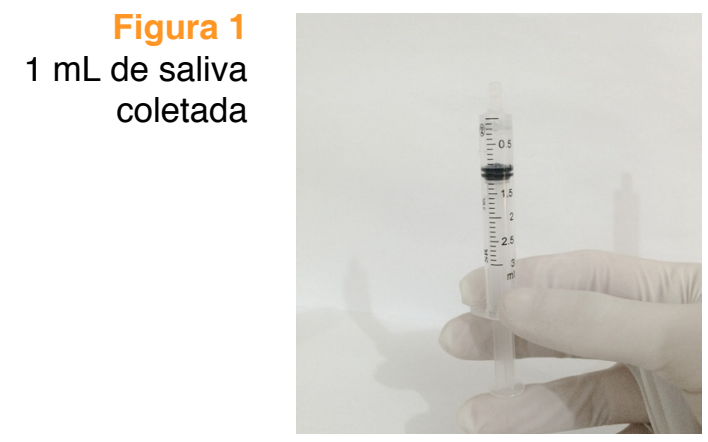

Fonte: autores.

Figura 3 Após dez minutos de interação entre saliva e ácido, foi imerso a fita de $\mathrm{pH}$ deixada interagir por 3 segundos, antes da leitura da fita.
Figura 2

$1 \mathrm{~mL}$ de saliva coletada misturada com

$3 \mathrm{~mL}$ de ácido clorídrico $0,005 \mathrm{~N}$

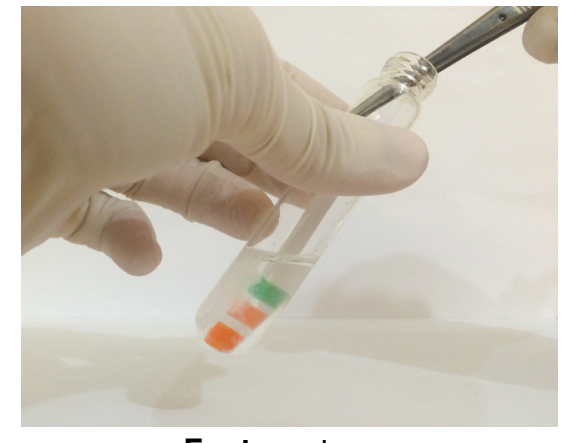

Fonte: autores.
Fonte: autores. 
Nas outras áreas

\section{Atividades multidisciplinares}

Durante o período do desenvolvimento deste trabalho, foram acompanhadas as diversas atividades desenvolvidas na Escola APAE, em áreas afins.

Os profissionais de outras áreas (Fisioterapia, Fonoaudiologia, Medicina, Psicologia, Pedagogia e Atividades artísticas-culturais) foram acompanhados neste estudo, sendo dois pontos observados; um deles em relação as alterações específicas percebidas pelos profissionais de cada área nos alunos com síndrome de Down, e também em relação as atividades realizadas com os mesmos.

\section{Preceitos Éticos}

Este projeto de pesquisa foi enviado ao Comitê de Ética em Pesquisa da Universidade de Passo Fundo através do site: http://www. uniara.com.br/comite/pfbrasil e aprovado pelo parecer CAAE número: 43050515.8.0000.5342. Um Termo de Consentimento Livre e Esclarecido foi entregue para assinatura dos pais e responsáveis previamente ao início das atividades na escola.

\section{RESULTADOS}

Na APAE/Passo Fundo existem 399 alunos sendo que desses, 23 são alunos com Síndrome de Down. Esses 23 alunos matriculados na instituição alguns frequentam a escola de manhã e outros à tarde, ressaltando que além de frequentarem a APAE, muitos desses alunos, também frequentam as escolas convencionais da cidade. O sistema de inclusão identifica os alunos com menor comprometimento intelectual e auxilia a introdução dos mesmos nas escolas da rede pública do município. Para estes, as atividades da escola APAE são realizadas em turnos inversos ao das atividades acadêmicas da escola convencional. Aos outros, com maior comprometimento, a escola APAE fica à disposição em horário integral.

Na prática odontológica da APAE, todos os pacientes com SD são atendidos (23 alunos/100\%) (Tabela 1). Os atendimentos fazem parte do Projeto de Extensão e nele são realizadas consultas semanais, conforme a demanda existente. Alguns pacientes menores são acompanhados pelos pais e/ou responsáveis, mas os mais velhos, geralmente não oferecem resistência ao atendimento odontológico. 
Tabela 1: Característica da amostra APAE/Passo Fundo, 2015.

\begin{tabular}{|l|c|c|}
\hline Alunos APAE/ Passo Fundo & N & $\%$ \\
\hline Gênero & & \\
\hline Masculino & 10 & 43,5 \\
\hline Feminino & 13 & 56,5 \\
\hline Total & 23 & 100 \\
\hline Idade & & \\
\hline$<05$ anos & 2 & 8,7 \\
\hline 5 a 12 anos & 5 & 21,7 \\
\hline 12 a 20 anos & 8 & 34,8 \\
\hline$>20$ anos & 8 & 34,8 \\
\hline Total & 23 & 100 \\
\hline Tipo de dentição & & \\
\hline Dentição decídua & 2 & 8,7 \\
\hline Dentição mista & 5 & 21,7 \\
\hline Dentição permanente & 16 & 69,6 \\
\hline Total & 23 & 100 \\
\hline
\end{tabular}

Os alunos que foram avaliados na APAE possuem alto índice de cárie, na dentição permanente (CPOD médio de 12,6) (Tabela 2).

Tabela 2: Característica do Odontograma dos alunos da APAE/Passo Fundo, 2015.

\begin{tabular}{|l|c|c|}
\hline Odontograma & Mínimo & Máximo \\
\hline Ceod & & \\
\hline Dentes cariados & 2 & 15 \\
\hline $\begin{array}{l}\text { Dentes extraídos ou indicados para } \\
\text { extração }\end{array}$ & 1 & 12 \\
\hline Dentes obturados & 0 & 8 \\
\hline Índice ceod médio: 8,23 & & \\
\hline CPOD & & \\
\hline Dentes Cariados & 3 & 12 \\
\hline Dentes perdidos & 0 & 8 \\
\hline Dentes Obturados & 0 & 15 \\
\hline Índice CPOD médio: 12,6 & & \\
\hline
\end{tabular}

$\mathrm{Na}$ avaliação clínica, durante o exame físico, foram encontradas as seguintes alterações: macroglossia, hipotonia lingual, língua fissurada, dentes conóides, bruxismo, cárie. Em relação ao item periodontal, como diagnósti$\mathrm{co}$, apresentaram gengivite, periodontite, cálculos supragengival e subgengival. Constatou-se também que muitos ficavam as maiores partes do tempo com a boca entreaberta, respirando pela cavidade bucal. Quanto à posição 
dental na arcada, constatou-se uma alta frequência de giroversões.

Sobre as anormalidades no Sistema Estomatognático (SE) desses pacientes encontramos os seguintes dados comparativos (Quadro 1, 2 e 3).

Quadro 1: Anormalidades periodontais dos alunos da escola APAE/ Passo Fundo.

\begin{tabular}{|c|c|c|c|c|c|c|}
\hline Alterações & $\begin{array}{c}\text { Gengi- } \\
\text { vite }\end{array}$ & $\begin{array}{c}\text { Peri- } \\
\text { odontite }\end{array}$ & Cálculo & $\begin{array}{c}\text { PV } \\
\text { (placa } \\
\text { visível) }\end{array}$ & $\begin{array}{c}\text { Re- } \\
\text { cessão }\end{array}$ & $\begin{array}{c}\text { Mobili- } \\
\text { dade }\end{array}$ \\
\hline Presença & Sim & Sim & Sim & Sim & Sim & Não \\
\hline Ausência & Não & Não & Não & Não & Não & Sim \\
\hline
\end{tabular}

Quadro 2: Anormalidades ósseo-musculares do SE nos alunos da escola APAE/ Passo Fundo.

\begin{tabular}{|c|c|c|c|c|c|}
\hline Alterações & $\begin{array}{c}\text { Hipotonia } \\
\text { (lábio e } \\
\text { língua) }\end{array}$ & $\begin{array}{c}\text { Palato } \\
\text { Ogival }\end{array}$ & Macroglossia & $\begin{array}{c}\text { Língua } \\
\text { Fissurada }\end{array}$ & $\begin{array}{c}\text { Prog- } \\
\text { natismo }\end{array}$ \\
\hline Presença & Sim & Sim & Sim & Sim & Sim \\
\hline Ausência & Não & Não & Não & Não & Não \\
\hline
\end{tabular}

Quadro 3: Alterações dentárias nos alunos da escola APAE/ Passo Fundo.

\begin{tabular}{|l|c|c|c|c|c|c|}
\hline Alterações & $\begin{array}{c}\text { Gi- } \\
\text { roversão }\end{array}$ & $\begin{array}{c}\text { Agene- } \\
\text { sias }\end{array}$ & $\begin{array}{c}\text { Tauro- } \\
\text { dontia }\end{array}$ & $\begin{array}{c}\text { Brux- } \\
\text { ismo }\end{array}$ & $\begin{array}{c}\text { Hipoplasia } \\
\text { esmalte }\end{array}$ & $\begin{array}{c}\text { Dentes } \\
\text { conóides }\end{array}$ \\
\hline Presença & Sim & Sim & Não & Sim & Não & Sim \\
\hline Ausência & Não & Não & Sim & Não & Sim & Não \\
\hline
\end{tabular}

De acordo com os exames realizados, alguns pacientes possuíam agenesias, sendo a mais frequente de incisivos laterais superiores.

A presença de placa visível foi comum a todos pacientes e, percebeu-se que quando mencionada a necessidade da higiene oral, a orientação de higiene, a possibilidade de técnicas alternativas para compensar a dificuldade motora, o retorno dos pacientes foi relativo ao comprometimento neurológico e a associação de outras patologias, necessitando sempre do cuidador para realizar ou auxiliar nesta tarefa.

Durante as avaliações odontológicas pode-se observar que os pacientes com síndrome de Down dividem-se principalmente em relação a patologia apresentada. Quando o diagnóstico é único da SD, o comprometimento neurológico é pequeno, conseguindo orientar e educar para a saúde bucal, e o retorno das tarefas ocorrem frequentemente. No entanto, quando há associações de síndromes, como, por exemplo, a associação com o autismo, até mesmo o exame clínico foi limitado. Nestes casos, o controle de placa apresentava-se quase inexistente e a saúde bucal estava mais comprometida. 
Durante as consultas odontológicas foram realizados alguns testes salivares. Neste caso, a dificuldade encontrada foi maior, pois alguns dos alunos não colaboravam e outros não permitiam a coleta da saliva. Em apenas 4 alunos foi realizada a coleta conforme o protocolo do produto (Fusion/ Universal( ${ }^{\circledR}$ ). $O$ fluxo de saliva destes pacientes também se encontrou alterada. Para a coleta de $1 \mathrm{ml}$ de saliva o tempo variou entre 5 a 30 minutos, sendo que um dos pacientes apresentava xerostomia. Na determinação do $\mathrm{pH}$ bucal, os valores encontrados variaram entre $\mathrm{pH} 2$ e 3 (Figura 4), constituindo um meio extremamente ácido.

Figura 4

Comparação da fita do paciente com a tabela cedida pelo fabricante. Neste caso, o padrão mais próximo, quando comparada foi $\mathrm{pH}=2$.

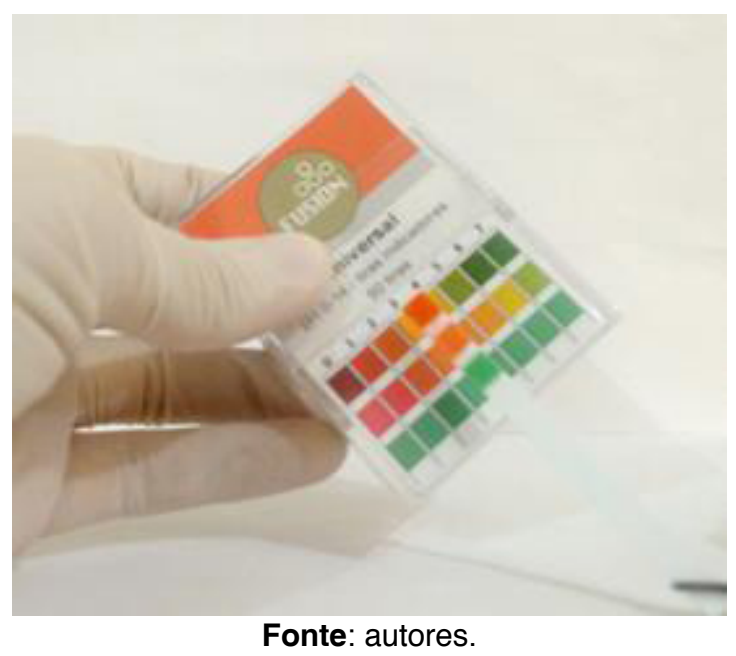

Durante o acompanhamento do projeto, outras atividades na escola foram observadas, segue abaixo os relatos dos profissionais das outras áreas e as principais observações:

\section{Fisioterapia}

De acordo com o profissional que acompanha os alunos com SD na escola APAE, na área da fisioterapia, não é observado um "padrão sindrômico". Porém, alguns apresentam "alteração na coordenação, percepção e no equilíbrio". Essas alterações são classificadas como "características secundárias" pelos profissionais dessa área, e está intimamente ligada a presença ou não de outras síndromes. Nos casos das crianças com SD e que possuem alterações ou outras características sindrômicas associadas o comprometimento sempre é maior, tanto físico quanto neurológico. 
Nesta área, os pacientes apresentavam algumas características bem específicas quando comparadas com outras síndromes. Tanto na linguagem quanto nos aspectos da motricidade orofacial são distintos em cada paciente, de acordo com o nível de comprometimento mental. Para haver um prognóstico da linguagem mais adequado, a fonoaudióloga da APAE, recomendada a avaliação auditiva de cada paciente, porém nem sempre é possível, "este serviço é solicitado na escola, mas não é disponível". O progresso do "desenvolvimento cognitivo é variável", e "sempre apresenta algum retardo", embora em alguns pacientes "foi possível alfabetização". Certamente as características mais citadas nesta área foram "a hipotonia de língua e a ausência do vedamento labial".

Na APAE Passo Fundo, os profissionais da fonoaudiologia, utilizam o simbolismo e o lúdico para que os pacientes aprendam e se desenvolvam cada vez mais.

\section{Medicina}

O profissional da área médica da instituição APAE de Passo Fundo constatou que os pacientes com Down, apresentam "problemas respiratórios frequentes e alguns exibiram problemas cardíacos graves, porém tratados e controlados". A grande maioria dos pacientes possuem "seus" médicos, que os acompanham desde muito precocemente. Porém "para situações eventuais e patologias cotidianas (gripe, sinusites e pneumonias) utilizam o serviço oferecido pela escola". Normalmente, ainda segundo relatos da instituição, "os pacientes com síndrome de Down, possuem especialmente cardiologistas e neurologistas que os acompanham simultaneamente".

\section{Psicologia}

Na área psicológica, "podemos categorizar um padrão" para esses pacientes. Esses, apresentam um "atraso no desenvolvimento neuropsicomotor, seu entendimento é regressivo, o reconhecimento das cores é diferente, e a fala se apresenta mais tardiamente". Durante algumas atividades lúdicas com desenhos e pinturas sobre odontologia, percebe-se a dificuldade nas cores, normalmente, a pintura se limita a uma cor, ou 3 no máximo. Para esses atendimentos, as primeiras consultas são feitas com os pais ou responsáveis e depois só com o paciente. "É comum que os pais também precisem de ajuda", e nestes casos, é feito consultas só com os pais, depois, os pais e o paciente para posteriormente só o paciente. 


\section{Pedagogia}

$\mathrm{Na}$ área da educação a APAE não classifica/categoriza as deficiências, atendem pacientes com deficiência intelectual. Pelo fato dos pacientes serem diferentes não é categorizado um padrão característico, pois, por exemplo, alguns reconhecem bem as letras, outros já nem tanto e outros não reconhecem nada, devido a esse fato suas evoluções são muito particulares. Segundo o relato da pedagoga, "na escola se pratica a inclusão, nenhum aluno é visto pela situação especial que apresenta. O fato de ter a SD ou ter qualquer outra síndrome não o deixa diferente. A todos os alunos é oferecida a mesma terapia pedagógica, independente da patologia apresentada".

Artes

Essa área é muito focada e apreciada pelos alunos da instituição, não somente para os SD. Através de atividades lúdicas e momentos proporcionados pelo professor, os alunos podem expressar suas emoções e interagir com os amigos e colegas, "sendo o maior objetivo a possibilidade de socialização".

Atividades como o teatro e a dança ensinam e ajudam no convívio e na socialização desses alunos, no "senso corporal além de exercitar a mente e sua capacidade cognitiva". Já as aulas de pintura colaboram com a canalização e expressão das suas diversas emoções e sentimentos, além de ajudar na capacidade motora desses indivíduos.

Uma das atividades presenciada durante este estudo foi a oficina de beleza. Neste dia especial, uma loja de cosméticos da cidade disponibilizou seus profissionais a passar à tarde na instituição promovendo alguns cuidados estéticos para esses alunos. Esses receberam corte de cabelo masculino e feminino, no reforço da sua autoestima. Nas mulheres foi realizada maquiagem, pintura de unhas, enquanto nos homens foi realizada a barba. Neste grupo todos os alunos eram adultos.

\section{DISCUSSÃO}

No Brasil estima-se que existam 300.000 pessoas com essa trissomia, em uma proporção de uma criança que nasce com Down para cada 600 nascimentos (IBGE, 2010). Na APAE de Passo Fundo, RS, entre 399 alunos da instituição, 23 apresentam a síndrome de Down, totalizando 5,8\% de alunos com essa síndrome na instituição, um número alto se comparado com a proporção de nascimentos no Brasil, mas esperado, pelo fato da escola ser referência em pessoas com necessidades especiais.

No presente trabalho, foram avaliadas inúmeras características dos pacientes com síndrome de Down. A variedade dos achados encontrados, os odontológicos ou os sistêmicos coincidem com os citados na literatura. Em relação às características dentomaxilo-faciais dos pacientes da APAE verificamos a presença de atresia palatina, língua fissurada, pseudo-macro- 
glossia, tónus labial diminuído, subdesenvolvimento da maxila e do terço médio da face, nariz pequeno, abóbada palatina baixa e estreita, atraso significativo da erupção dentária da dentição temporária e permanente, fluxo salivar diminuído, perfil plano ou prognático, alta incidência de bruxismo noturno, hipotonicidade, hiperflexibilidade, flacidez de ligamentos, movimento lingual impreciso e lento, implantação irregular dos dentes, agenesias ou anodontias, dentes supranumerários, maior frequência de oclusão cruzada anterior e posterior, anomalias da forma mais frequentes nos dentes permanentes e temporários (dentes conoides), defeitos do esmalte, doença periodontal e menor prevalência de cárie.

Dentre as manifestações mais comuns destacou-se o grande número de pacientes com palato ogival, estreito. Característica óssea comum em citações da literatura relacionada a esta sindrome (VIEIRA et al., 2010; AREIAS, 2011). Em oposição a presença de fissuras, descritas como de baixa prevalência (cerca de 0,5\%) nestes pacientes (BERTHOLD et al., 2004).

No ambiente da APAE constatou-se um grande número de pacientes com doença periodontal, alto índice de placa visível, presença de sangramento gengival e cálculo. A alta frequência de doença periodontal pode ser atribuída à dificuldade na higienização bucal desses pacientes, por apresentarem deficiências motora, neurológica e hipotonia muscular. Nos casos examinados foi possível a verificação de elevado acúmulo do biofilme bacteriano, o que portanto, aumenta a suscetibilidade à doença periodontal. Entretanto, a deficiência imunológica é também um fator que contribui para a evolução da doença periodontal nestes pacientes. A redução numérica dos linfócitos e os defeitos funcionais de quimiotaxia e fagocitose celular dos neutrófilos e monócitos constituem as alterações mais comumente observadas na resposta imunológica nos pacientes com síndrome de Down, o que os torna altamente suscetíveis ao desenvolvimento da doença periodontal frente à pobre higiene bucal (VIEIRA et al., 2010).

Na avaliação da doença cárie, foi possível verificar alto índice de cárie (CPOD médio de 12,6), pH salivar baixo ( $\mathrm{pH} 2$ e 3), presença de placa visível o que considera uma saúde bucal insatisfatória com necessidade de tratamento odontológico e pouca ação preventiva. A literatura nesta área não se apresenta uniforme, ora encontramos publicações indicando baixo índice de cáries em pacientes com síndrome de Down, ora outros artigos indicam alta atividade da doença. No caso dos estudos que salientam a alta atividade da doença, indicando uma saúde oral corriqueiramente deficiente ou precária (CHANG, 2013; VERÍSSIMO et al., 2013; SANTOS et al., 2010), isto manifesta-se e justifica-se pelo déficit intelectual e/ou motor e pela incapacidade desses pacientes no desempenho correto dos procedimentos necessários à remoção mecânica da placa bacteriana. Outro fator importante, citado pela literatura, é a falta de conhecimento dos cuidadores em relação a possibilidade de limpeza e das técnicas corretas de higiene oral (VERÍSSIMO et al., 2013). 
Makowiecky (1984) estudou a prevalência de cárie em 196 indivíduos com déficit mental de 6 a 20 anos de idade. A cárie foi prevalente em 96,4\% dos pacientes examinados, sendo que o índice CPOD foi 9,06. Um estudo mais recente analisou a experiência de cárie em superfícies de dentes permanentes e decíduos (ceo-s e CPO-S), verificando um percentual de 6,23 no sexo feminino e 3,58 no sexo masculino, com média de 5,27 no grupo total (GOLÇALVES et al., 2010). Outro estudo teve como prevalência de cárie dentária 70,8\% (XAVIER et al., 2012), resultado semelhante ao relatado por Sbroglio et al. (2008), tendo encontrado 69,9\%. No entanto, superior ao encontrado por Dávila et al. (2006), que descreve 53,0\% de prevalência em seu estudo, resultando em uma média de CPOD de 5,3, e também o resultado de Oliveira; Luz; Paiva (2007), que relata 4,9 na média de CPOD.

A pesquisa realizada por Areias et al. (2012) elucida outra perspectiva, os fatores envolvidos na menor prevalência de cárie dental na síndrome de Down (SD). Em comparação com seus irmãos, crianças com SD apresentaram contagens mais baixas de estreptococos mutans em paralelo com uma taxa de livres de cárie maior, apesar da evidência de hipossalivação. Embora as crianças SD tiveram uma menor prevalência de cárie dentária em comparação com seus irmãos, a história de cárie, evidenciada por CPO-d / CPO-D, não foi significativamente diferente entre os dois grupos. Neste estudo foi citado que os pacientes sentiam-se motivados a higienizar corretamente a cavidade bucal no entanto foi relatada a necessidade de auxilio durante esta tarefa.

A dificuldade motora não permite uma eficiente higiene bucal. A educação para a saúde bucal, incluindo as técnicas de higiene bucal, devem ser aplicadas, precocemente, a pacientes com síndrome de Down, tendo em vista suas deficiências motoras e neurológicas e a necessidade da prevenção das doenças dentais. Observando as características apresentadas pelos portadores de síndrome de Down, a prevenção das doenças bucais é fundamental (CAMERA et al., 2011).

Segundo Camera (2011), nas observações de seu estudo, as crianças têm uma grande dificuldade motora para a realização da higienização bucal e que algumas, inclusive, não permitem que os pais realizem a sua escovação. Essa situação não só comprova a prevalência da doença, como também possibilita demonstrar aos pais as reais causas dos problemas bucais de seus filhos e a propensão de alterações devido sua condição sistêmica, como demostraram interesse, responsabilidade e compromisso em estabelecer hábitos e estratégias de higiene bucal para seus filhos, a partir disso. Durante o teste salivar, realizado na APAE, encontrou-se valor de $\mathrm{pH}$ ácido quando comparado com a normalidade. Nos pacientes que realizaram o teste o valor de $\mathrm{pH}$ foi 2 e 3 , sendo que o $\mathrm{pH}$ médio da saliva estimulada deveria estar entre os 6.5 - 7.4, dependendo das concentrações de bicarbonato e fosfato (AREIAS, 2011). O pH crítico para iniciar o processo de desmineralização é de 4,5 (AREIAS, 2011). Na literatura há casos em que não foi encontrada diferença estatística no $\mathrm{pH}$ de pacientes com Down quando comparado com o grupo controle (YARAT et al., 1999; ENSSLIN et al., 
2009). Mas, a literatura cita casos em que valores inferiores de $\mathrm{pH}$ salivar também foram relatados em indivíduos com síndrome de Down (SIQUEIRA; NICOLAU, 2002). Fatores como o método de coleta, procedimento usado para mensuração de $\mathrm{pH}$, faixa etária estudada e outros fatores podem ter influenciado os resultados.

Além disso, verifica-se relatos descritos da hipossalivação com o uso de medicamentos, como anticonvulsionantes, antipsicóticos, ansiolíticos, antiepiléticos e antidepressivos. Esses medicamentos induzem alterações na composição eletrolítica e orgânica da saliva, reduzindo sua capacidade tampão com consequente aumento da perda mineral da estrutura dentária e comprometimento da remineralização, podendo aumentar o risco à cárie. (DOMINGUES et al., 2015). Exatamente como podemos verificar nos casos estudados na APAE, onde a totalidade dos alunos possuem prescrição e uso continuo dos medicamentosa citados acima.

Esses achados literários apenas comprovam e reforçam a necessidade de programas preventivos para reverter esse quadro para que a higiene bucal tenha cada vez mais importância em políticas multidisciplinares, bem como nas atividades interdisciplinares.

Durante a realização do estudo na APAE, foram realizadas conversas com os profissionais atuantes no mesmo ambiente, na tentativa de verificar as características mais evidentes além das previstas na área odontológica. Uma das características médicas citadas, durante o estudo foi a alta frequência de problemas respiratórios e cardiopatias em SD.

Sabe-se que a prevalência de anomalias cardíacas congênitas em pacientes com síndrome de Down é de 40 a 50\%. Dos pacientes que apresentam cardiopatia congênita, metade manifesta defeito no septo atrioventricular (DSAV). Em um estudo de 10 anos de revisão de DSAV, foi observada alta mortalidade quando relacionado à síndrome de Down (MOURATO et al., 2014). As anormalidades cardíacas congênitas, a hipertensão pulmonar, a hipoplasia pulmonar, a obstrução das vias aéreas superiores e imunodeficiência afetam consequentemente a função pulmonar desses pacientes, sendo o fator imunológico uns dos principais fatores (GARCÍA et al., 2013).

No campo da fonoaudiologia, tanto o profissional da escola APAE, quanto a literatura citam a hipotonia lingual como uma característica nos pacientes com síndrome de Down. O paciente apresenta cavidade oral de tamanho reduzido, alterações nos órgãos que compõem o sistema estomatognático, ocasionando distúrbios fonoarticulatórios. A hipotonia muscular provoca um desequilíbrio de forças entre os músculos orais e faciais, alterando a arcada dentária, dando um aspecto de projeção mandibular e contribuindo para que a língua assuma uma posição inadequada. A respiração oral, além de deixar a criança mais suscetível a infecções respiratórias, altera seu palato e dificulta a articulação dos sons, sendo a fala um dos maiores problemas existentes nestes indivíduos (BARATA; BRANCO, 2010).

Após a realização deste estudo e com a possibilidade de descrever seus achados, só parece-nos indiscutível a necessidade da importância 
na integração das diferentes densidades de tecnologias e de complexidade da atenção à saúde. O próprio Ministério da Saúde ilustra e indica a integração nos recursos para a comunidade. Compartilhar cuidados é também a corresponsabilização do processo do cuidado entre profissionais, o sujeito sob cuidado e sua família. Os melhores resultados terapêuticos são obtidos quando a equipe multiprofissional trabalha em conjunto, discutindo os avanços e novas propostas de tratamento (BRASIL, 2013).

$\mathrm{E}$, vale ressaltar que, quando possível, a articulação com universidades e/ou serviços das diferentes especialidades é importante para o acompanhamento (BRASIL, 2013). Dessa forma há a prestação de serviço de forma voluntária e a experiência extencionista é adquirida, promovendo a formação profissional e humana do indivíduo.

CONCLUSÃO

Este estudo reforça a necessidade da integração entre as áreas dentro de qualquer ambiente que pretende realizar reabilitação. As necessidades dos pacientes com síndrome de Down se repetem muitas vezes na fisioterapia, na fonoaudiologia e na odontologia, e demais áreas. O fato dos alunos da Odontologia terem encontrado gengivite, periodontite, cálculo e má higiene oral, mostra uma relação direta com a dificuldade motora na apreensão da escova. Assim como, as hipotonicidades periorais com as alterações na fala.

Pode-se concluir que a necessidade de projetos desta natureza engrandece o aprendizado de todos envolvidos. A necessidade e as dificuldades apresentadas são minimizadas pelo grupo na resolução dos problemas. Esta experiencia promoveu uma integração da extensão com a comunidade da escola APAE em todos os sentidos.

REFERÊNCIAS

AREIAS, C. M. F. G. P. Efeito da composição da saliva na prevalência da cárie dentária em crianças com trissomia 21. 2011. Dissertação (Doutorado em Odontopediatria) - Faculdade de Medicina Dentária, Universidade do Porto, Porto, 2011.

AREIAS, C. et al. Reduced salivary flow and colonization by mutans streptococci in children with down syndrome. Clinics, v. 67, n. 9, p. 1007-1011, 2012.

BARATA, L. F.; BRANCO, A. Os distúrbios fonoarticulatórios na síndrome de down e a intervenção precoce. Revista CEFAC, São Paulo, v. 12, n. 1, p. 134-139, 2010.

BERTHOLD, T. B. et al. Síndrome de Down: aspectos gerais e odontológicos. Ver. Ciênc. Méd. Biol., vol. 3, n. 2, p. 252-260, 2004. 
BRASIL. Ministério da Saúde. Diretrizes de atenção à pessoa com síndrome de Down (2013). Disponível em: <http://bvsms.saude.gov.br/bvs/ publicacoes/diretrizes_atencao_pessoa_sindrome_down.pdf >. Acesso em: 25 jan. 2016.

CAMERA, G. T. et al. O papel do cirurgião-dentista na manutenção da saúde bucal de portadores de síndrome de Down. Odontol. Clín. Cient., Cascavel, v. 10, n. 3, p. 247-250, 2011.

CHANG, J.et al. Caries risk profile of Korean dental patients with severe intellectual disabilities. Spec Care Dentist, v. 20, n. 10, p. 1-7, 2013.

DÁVILA, M. E. G. I. L. M. et al. Caries dental en personas com retraso mental y síndrome de Down. Rev. Salud Pública, v. 8, n. 3, p. 207-213, 2006.

DOMINGUES, N. B. et al. Caracterização dos pacientes e procedimentos executados no serviço de atendimento a pacientes com necessidades especiais da Faculdade de Odontologia de Araraquara - UNESP. Ver. Odontol. UNESP, v. 44, n. 6, p. 345-350, 2015.

DURCE, K. et al. Atuação da fisioterapia na inclusão de crianças deficientes físicas em escolas regulares: uma revisão da literatura. $\mathbf{O}$ Mundo da Saúde, São Paulo, v. 30, n. 1, p. 156-159, 2006.

ENSSLIN, A. P. et al. Parâmetros salivares e dentários de indivíduos portadores de síndrome de Down em um munícipio do Rio Grande do Sul. Stomatos, Canoas, v. 15, n. 28, p. 58-66, 2009.

GARCÍA, M.et al. Infecciones respiratorias en niños con síndrome de Down. Neumol. Pediatr., v. 8, n. 1, p. 22-26, 2013.

GONÇALVES, S. S. et al. Levantamento das condições de cárie e doença periodontal na associação de portadores da síndrome de Down em Teresópolis-RJ. Ver. Odontol. São Paulo, São Paulo, v. 22, n. 1, p. 1924, 2010.

HADDAD, A. S. Odontologia para pacientes com necessidades especiais. São Paulo: Santos, 2007.

IBGE. INSTITUTO BRASILEIRO DE GEOGRAFIA E ESTATÍSTICA. Disponível em: <http://www.ibge.gov.br.> Acesso em: 20 maio 2015.

KASSAR, M. C. M.; REBELO, A. S. O “especial” na educação, o atendimento especializado e a educação especial. In: SEMINÁRIO NACIONAL DE PESQUISA EM EDUCAÇÃ̃O ESPECIAL, 4., Nova Almeida-Serra, 2011. Relatório final.

MAKOWIECKY, N. Índice CPOD de 196 excepcionais de 06 a 20 anos de idade, ambos os sexos, submetidos a anestesia geral para tratamento 
odontológico. Ver. Ciênc. Saúde, v. 1, n. 2, p. 47-57, 1984.

MOURATO, F. A.; VILLACHAN, L. R. R.; MATTOS, S. S. Prevalência e perfil das cardiopatias congênitas e hipertensão pulmonar na síndrome de Down em serviço de cardiologia pediátrica. Ver. Paul. Pediatr, São Paulo, v. 32, n. 2, p. 159-163, 2014.

OLIVEIRA, A. C. B.; LUZ, C. L. F.; PAIVA, S. M. O papel da saúde bucal na qualidade de vida do indivíduo com síndrome de Down. Arq. Odontol., v. 43, n. 4, p.162-168, 2007.

PERES, A. S.; PERES, S. H. C. S.; DA SILVA, R. H. A. Atendimento a pacientes especiais: reflexão sobre os aspectos éticos e legais. Rev. Fac. Odontol. Lins, Piracicaba, v. 17, n. 1, p. 49-53, 2005.

SANTAGELO, C.N. et al. Avaliação das características bucais de pacientes portadores de Sindrome de Down da APAE de Mogi das Cruzes - SP. Conscientiae Saúde, v. 7, n. 1, p. 29-34, 2008.

SANTOS, M. T. B. R.; BIANCARDI M, G. R. O.; JARDIM, J. R. Caries prevalence in patients with cerebral palsy and the burden of caring for them. Spec Care Dentist, São Paulo, v. 30, n. 5, p. 206-210, 2010.

SANTOS, M.; MORIZON, G. Manejo Clínico de niños con síndrome de Down. Pediatría, v. 15, n. 1, p. 29-33, 1999.

SBROGLIO, T. et al. Prevalência e severidade de cárie dentária e necessidade de tratamento odontológico em pacientes especiais. Ver. ABO Nac., v. 15, n. 6, p. 352-356, 2008.

SILVA, L.C.P.; CRUZ, R..A. Odontologia para pacientes com necessidades especiais: protocolos para o atendimento clínico. São Paulo: Santos, 2009.

SILVA, L. C. P. Manejo de pacientes com necessidades especiais nos cuidados de saúde. São Paulo: Santos, 2010.

SIQUEIRA W. L.; NICOLAU, J. Stimulated whole saliva components in children with Down syndrome. Spec Care Dentist, São Paulo, v. 22, n. 6, p. 226-230, 2002.

STRACHAN, T.; READ, A. P. Genética molecular humana. 2. ed. Porto Alegre: Artmed, 2002.

VERÍssimo, A. H.; AZEVEDO, I. D.; RÊGO, D. M. Perfil Odontológico de pacientes com necessidades especiais assistidos em hospital pediátrico de uma universidade pública brasileira. Pesq. Bras. Odontoped. Clin. Integr, João Pessoa, v. 13, n. 4, p. 329-335, 2013.

VIEIRA, T. R.; CASTRO, A. A.; PÉRET, L. A. F. Alterações periodontais as- 
sociadas às doenças sistêmicas em crianças e adolescentes. Rev. Paul. Pediatr., v. 28, n. 2, p. 237-243, 2010.

XAVIER, A. F. C. et al. Prevalencia de anormalidades bucales y caries dental en portadores de síndrome de Down. Acta Odontol. Venez., Venezuela, v. 50, n. 4, 2012.

YARAT, A. et al. Salivary sialic acid, protein, salivary flow rate, $\mathrm{pH}$, buffering capacity and caries in subjects with Down's syndrome. Journal of Dent., v. 27, n. 2, p. 115-118, 1999.

Data de recebimento: 30 de março de 2017.

Data de aceite para publicação: 15 de maio de 2017. 